\title{
Effect of phenolic acids on glucose and organic acid metabolism by lactic acid bacteria from wine
}

\author{
Francisco M. Campos*, Ana R. Figueiredo, Tim A. Hogg, José A. Couto \\ Escola Superior de Biotecnologia, Universidade Católica Portuguesa, Rua Dr. António Bernardino de Almeida, 4200-072 Porto, Portugal
}

Keywords:

Phenolic acids

Lactic acid bacteria

Oenococcus oeni

Lactobacillus hilgardii

Glucose metabolism

Organic acid metabolism

Malolactic fermentation

Wine

A B S T R A C T

The influence of phenolic ( $p$-coumaric, caffeic, ferulic, gallic and protocatechuic) acids on glucose and organic acid metabolism by two strains of wine lactic acid bacteria (Oenococcus oeni VF and Lactobacillus hilgardii 5) was investigated. Cultures were grown in modified MRS medium supplemented with different phenolic acids. Cellular growth was monitored and metabolite concentrations were determined by HPLC-RI. Despite the strong inhibitory effect of most tested phenolic acids on the growth of $O$. oeni $\mathrm{VF}$, the malolactic activity of this strain was not considerably affected by these compounds. While less affected in its growth, the capacity of L. hilgardii 5 to degrade malic acid was clearly diminished. Except for gallic acid, the addition of phenolic acids delayed the metabolism of glucose and citric acid in both strains tested. It was also found that the presence of hydroxycinnamic acids ( $p$-coumaric, caffeic and ferulic) increased the yield of lactic and acetic acid production from glucose by 0 . oeni VF and not by L. hilgardii 5 . The results show that important oenological characteristics of wine lactic acid bacteria, such as the malolactic activity and the production of volatile organic acids, may be differently affected by the presence of phenolic acids, depending on the bacterial species or strain.

\section{Introduction}

Lactic acid bacteria are a group of Gram positive, aerotolerant bacteria which produce lactic acid from carbohydrate metabolism. Some bacteria from this group can tolerate the stressful conditions of the wine environment, specifically, low $\mathrm{pH}$, presence of ethanol and sulphur dioxide, low temperature and low nutrient concentrations (Fleet, 1997). Their growth and metabolic activity result in changes to wine composition which directly influences its final quality. Lactic acid bacteria are generally responsible for the malolactic fermentation, which is desirable in most red wines and in some styles of white wine. During this process these bacteria multiply and decarboxylate L-malic acid to L-lactic acid, resulting in an overall deacidification of the wine. Also, lactic acid bacteria may affect the wine aroma by modifying fruit-derived compounds and producing aroma active compounds which may have a positive or negative impact on wine quality (de Revel et al., 1999; Henick-Kling, 1995; Lonvaud-Funel, 1999). Oenococcus oeni is the main lactic acid bacteria responsible for the occurrence of malolactic fermentation (Fugelsang, 1997). Nowadays, strains of this species are widely used as malolactic starter cultures in the wine industry.

\footnotetext{
* Corresponding author. Tel.: +351 225580045; fax: +351 225090351.

E-mail address: fmcampos@mail.esb.ucp.pt (F.M. Campos).
}

Residual sugars, mainly hexoses and pentoses, and other substrates can also be metabolized by these bacteria originating important changes in wine quality (Lonvaud-Funel, 1999). Some strains of lactic acid bacteria are known to cause wine spoilage, producing "off-flavours" and other undesirable changes (Sponholz, 1992). Lactobacillus hilgardii is often associated with the spoilage of Port and other fortified wines (Couto and Hogg, 1994; de Revel et al., 1994; Dicks and van Vuuren, 1988). Strains from this species are well known for their ability to tolerate the high ethanol concentrations attained in these wines. Being heterofermentative bacteria, both $O$. oeni and L. hilgardii metabolize D-glucose via the hexose monophospate/pentose-phosphate pathway, yielding lactic acid, carbon dioxide and ethanol or acetic acid as final products. The ratio ethanol/acetic acid depends on the redox potential and on the presence of pantothenic acid in the medium (Richter et al., 2001; Zaunmuller et al., 2006).

Lactic acid bacteria are also known to metabolize citric acid, producing lactic acid, diacetyl, acetoin and acetic acid (Fugelsang, 1997). The relative amounts of the products of citrate metabolism depend on the presence or absence of glucose (Ramos and Santos, 1996). Several authors have reported that wine lactic acid bacteria metabolize organic (citric and L-malic) acids before D-glucose depending on growth conditions (Pimentel et al., 1994; Rozes et al., 2003; Saguir and de Nadra, 1996). 
Phenolic compounds are one of the most abundant groups of chemical compounds in wine and have an extremely important impact on its sensorial characteristics. These compounds exist in the grapes and in the wood of the barrels used for wine maturation. Phenolic acids (hydroxybenzoic and hydroxycinnamic acids) are relatively abundant in wine (Reguant et al., 2000) and exist mostly in combined forms as tartaric acid esters, anthocyanin esters or soluble tannins (Macheix et al., 1990). The hydrolysis of these compounds during alcoholic fermentation causes the release of "free" phenolic acid molecules. Although hydroxybenzoic and hydroxycinnamic acids have similar structures (Fig. 1), they can have different effects on the growth and metabolism of wine lactic acid bacteria. Previously published studies suggest that gallic acid can stimulate growth and malolactic activity of some strains of lactic acid bacteria (Alberto et al., 2001; Vivas et al., 1997) and delay the production of acetic acid from citric acid in $O$. oeni (Reguant et al., 2000). On the other hand, other authors found that some phenolic acids delayed the conclusion of the malolactic fermentation by this bacterium (Reguant et al., 2000; Vivas et al., 1997). Hydroxycinnamic acids (particularly p-coumaric acid) are known to inhibit growth of a variety of microorganisms including wine-spoilage strains of L. collinoides and L. brevis (Stead, 1993), L. hilgardii and O. oeni (Campos et al., 2003).

In this study, five phenolic acids, which occur naturally in wines, were tested for their effects on glucose and organic (citric and L-malic) acids metabolism by $O$. oeni and $L$. hilgardii.

\section{Methods}

\section{Bacteria and growth conditions}

The bacterial strains used were L. hilgardii 5, a wild strain from the Escola Superior de Biotecnologia da Universidade Católica Portuguesa (ESBUCP) culture collection originally isolated from Port wine (Couto and Hogg, 1994), and O. oeni VF, a commercial starter culture strain, VINIFLORA OENOS from CHRISTIAN HANSEN (Hrevidre, Denmark). Initial cultures (pre-cultures) were prepared in MRS/TJ broth medium: 50:50 mixture of MRS (de Man, Rogosa and Sharpe) from BIOKAR DIAGNOSTICS (Beauvais, France) and TJ (Tomato Juice broth) from DIFCO (Detroit, MI). This mixed medium was previously found to enhance growth of both strains (particularly O. oeni VF) comparatively to MRS alone. The initial $\mathrm{pH}$ of the medium was adjusted to 4.5 with a concentrated $(6 \mathrm{M})$ hydrochloric acid solution before sterilizing $\left(121^{\circ} \mathrm{C}, 15 \mathrm{~min}\right)$. After sterilization, ethanol $(99.5 \% \mathrm{v} / \mathrm{v})$ was added to the medium to obtain a final concentration of $5 \% \mathrm{v} / \mathrm{v}$.

Growth and metabolism experiments were performed in MRS broth supplemented with L-malic acid $\left(4.0 \mathrm{~g} \mathrm{~L}^{-1}\right)$ from MERCK (Darmstadt, Germany). The approximate composition of this medium before heat sterilization $\left(121^{\circ} \mathrm{C}, 15 \mathrm{~min}\right.$ ) was (in $\mathrm{g} \mathrm{L}^{-1}$

\begin{tabular}{|c|c|c|}
\hline Group & Chemical structure & Name \\
\hline Hydroxybenzoic acids & $\mathrm{OH}$ & $\begin{array}{l}\mathrm{R}^{\prime}=\mathrm{H} ; \mathrm{R}=\mathrm{OH}-\text { Protocatechuic } \\
\quad \text { Acid } \\
\mathrm{R}^{\prime}=\mathrm{R}=\mathrm{OH}-\text { Gallic acid }\end{array}$ \\
\hline Hydroxycinnamic acids & $\overbrace{\mathrm{R}}^{\mathrm{HO}}$ & $\begin{array}{l}\mathrm{R}^{\prime}=\mathrm{R}=\mathrm{H}-p \text {-Coumaric acid } \\
\mathrm{R}^{\prime}=\mathrm{H} ; \mathrm{R}=\mathrm{OH}-\text { Caffeic acid } \\
\mathrm{R}^{\prime}=\mathrm{H} ; \mathrm{R}=\mathrm{OCH}_{3}-\text { Ferulic acid }\end{array}$ \\
\hline
\end{tabular}

Fig. 1. Structural formulae of the phenolic compounds used in this work. distilled water): polypeptone -10 , meat extract - 10 , yeast extract 5 , glucose -20 , Tween $80-1.08$, potassium hydrogenophosphate -5 , potassium acetate -5 , ammonium citrate -2 , magnesium sulphate 0.2 , manganese sulphate -0.05 and $\mathrm{L}$-malic acid -4 . Initial $\mathrm{pH}$ of the medium was adjusted to 4.5 before sterilization. After sterilization, ethanol $(99.5 \% \mathrm{v} / \mathrm{v})$ was added to the medium to obtain a final concentration of $5 \% \mathrm{v} / \mathrm{v}$.

Bacterial growth was determined by absorbance measurement at $660 \mathrm{~nm}$, using an UV/VIS UNICAM 8620 (Cambridge, UK) spectrophotometer.

Influence of phenolic acids on glucose and organic acids metabolism by $O$. oeni and L. hilgardii

Pre-cultures were grown aerobically to late exponential phase in MRS/TJ medium (four days at $25^{\circ} \mathrm{C}$ ), and then transferred to $100 \mathrm{~mL}$ flasks with growth medium MRS supplemented with different phenolic acids. Hydroxycinnamic ( $p$-coumaric, ferulic and caffeic) and hydroxybenzoic (protocatechuic and gallic) acids were added to the growth medium to obtain a final concentration of $500 \mathrm{mg} \mathrm{L}^{-1}$. These compounds were selected because of their ability to affect the growth of the tested strains (Campos et al., 2003). All phenolic compounds were obtained from SIGMAALDRICH (Steinheim, Germany). Fresh concentrated solutions of phenolic acids were prepared in ethanol $(99.5 \% \mathrm{v} / \mathrm{v})$ and added to the growth medium, after sterilisation. In the control assay only ethanol was added to the medium. The final ethanol concentration was $5 \% \mathrm{v} / \mathrm{v}$ in all assays.

Cultures were incubated aerobically at $25^{\circ} \mathrm{C}$, without agitation, for 8 days and samples were collected to monitor cellular growth and to measure the extracelullar concentration of glucose and organic acids. After absorbance measurement, samples were stored at $-20^{\circ} \mathrm{C}$ for later analysis of these compounds. Assays were made simultaneously and the whole experiment was repeated to verify the results.

A similar experiment was devised to test the influence of different concentrations of $p$-coumaric acid on glucose and organic acid metabolism of the two strains. This compound was chosen for its particularly inhibitory effect on growth of both strains (Campos et al., 2003). Cultures were prepared as described, with different concentrations of $p$-coumaric acid $\left(0,50,250\right.$ and $\left.500 \mathrm{mg} \mathrm{L}^{-1}\right)$ and incubated in the same conditions as above. Samples were collected and frozen for later analysis.

\section{Determination of metabolite concentrations}

Glucose and organic acids concentrations were determined by HPLC, using a BECKMAN GOLD system equipped with a Refractive Index (RI) detector. Analysis was performed using a BIORAD (Richmond, CA) AMINEX HPX-87H $(300 \times 7.8 \mathrm{~mm})$ column. Operation conditions were as follows: mobile phase, $\mathrm{H}_{2} \mathrm{SO}_{4} 2.5 \mathrm{mM}$; flow rate, $0.6 \mathrm{~mL} \mathrm{~min}^{-1}$; column temperature, $50{ }^{\circ} \mathrm{C}$; injection loop volume, $20 \mu \mathrm{L}$. Samples were microfiltered using $0.45 \mu \mathrm{m}$ syringe filters prior to injection on the HPLC system. Peak identification was based on the relative retention times determined by injection of standard solutions. Quantification was performed using calibration curves.

\section{Statistical analysis}

Lactic and acetic acid yields from glucose were calculated using the data values obtained after total consumption of L-malic and citric acids. Analyses of variance (ANOVA) and Tukey's HSD (honestly significant differences) for samples of different sizes (Spjotvoll/Stoline test) were used to compare yield values between the 
different assays. All tests were performed using STATISTICA for Windows version 4.5 from STATSOFT (Tulsa, OK) at a confidence level of $95 \%(p=0.05)$.

\section{Results and discussion}

The results obtained indicate that, with the exception of gallic acid, all phenolic acids had a negative effect on growth of $L$. hilgardii 5 and 0 . oeni $\mathrm{VF}$, decreasing the growth rate and the maximum absorbance attained (Figs. 2a and 3a). This inhibitory effect was stronger in the case of $O$. oeni VF than in the case of L. hilgardii 5 and was higher in the presence of hydroxycinnamic acids ( $p$-coumaric, caffeic and ferulic acids) than in the presence of hydroxybenzoic acids (gallic and protocatechuic acids). These results agree with previously published results using the same strains (Campos et al., 2003).

Except for gallic acid, all phenolic acids had an adverse effect on the progress of the malolactic fermentation by L. hilgardii 5 , extending its completion time. This effect was most noticeable for ferulic and $p$-coumaric acids (Fig. 2c). Interestingly, despite the strong inhibitory effect of most tested phenolic acids on $O$. oeni VF growth (Fig. 3a), the malolactic activity of this strain was not considerably affected by their presence. Nevertheless, ferulic and p-coumaric acid slightly delayed the conclusion of the malolactic conversion by this organism (Fig. 3c). These findings are not totally unexpected considering that, as a starter culture, this strain was probably selected for its exceptional abilities to conduct malolactic fermentation under stressful conditions (Nielsen et al., 1996).

Glucose metabolism of $L$. hilgardii 5 started simultaneously with organic (L-malic and citric) acids metabolism (Fig. 2b-d). On the contrary, organic acids metabolism preceded glucose consumption by 0 . oeni VF (Fig. 3b-d), which is a desirable behaviour for a malolactic starter culture. The glucose metabolism of both strains seems to be related to their growth patterns which suggest that no increased glucose consumption was induced by the presence of phenolic acids in the growth medium.

Citrate metabolism occurred on the early growth stages of both strains (Figs. $2 \mathrm{~d}$ and $3 \mathrm{~d}$ ) contributing to the increase of the acetic acid concentration in the medium (Figs. $2 \mathrm{f}$ and $3 \mathrm{f}$ ). $p$-Coumaric and ferulic acids delayed the citrate consumption by L. hilgardii 5 (Fig. 2d). Citrate consumption by 0 . oeni VF was also negatively affected by the existence of phenolic acids in the medium, except for gallic acid (Fig. 3d).

In the case of L. hilgardii 5 no notable differences were found in the total acetic acid production between the control assay and the assays supplemented with phenolic acids (Fig. 2f, Table 1). In the
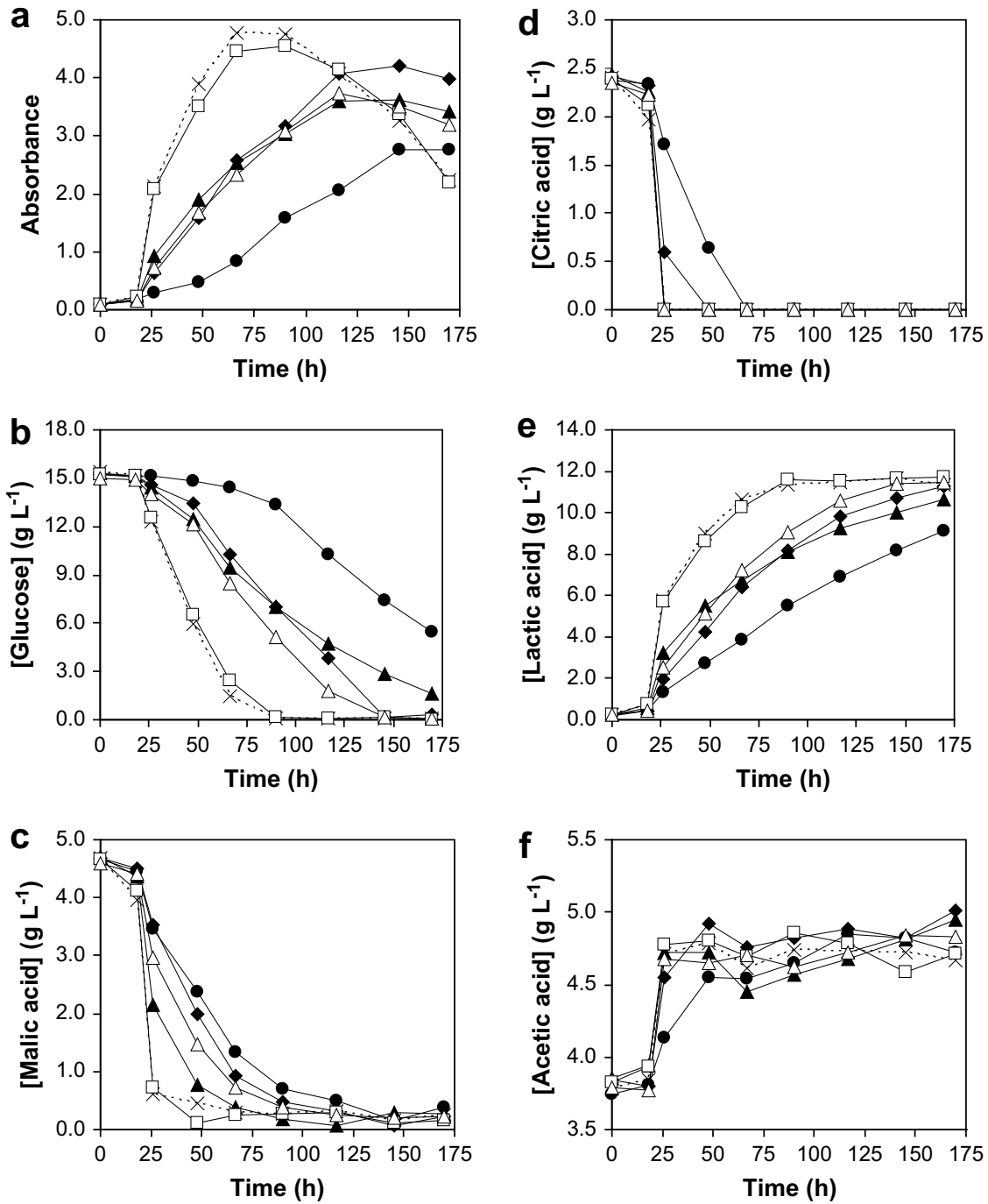

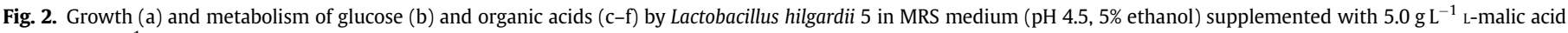
and $500 \mathrm{mg} \mathrm{L}^{-1}$ phenolic acids; $(\Delta)$ caffeic acid, $(\bullet)$ ferulic acid $(\bullet)$ p-coumaric acid, $(\square)$ gallic acid; $(\Delta)$ protocatechuic acid, $(\times)$ control. 

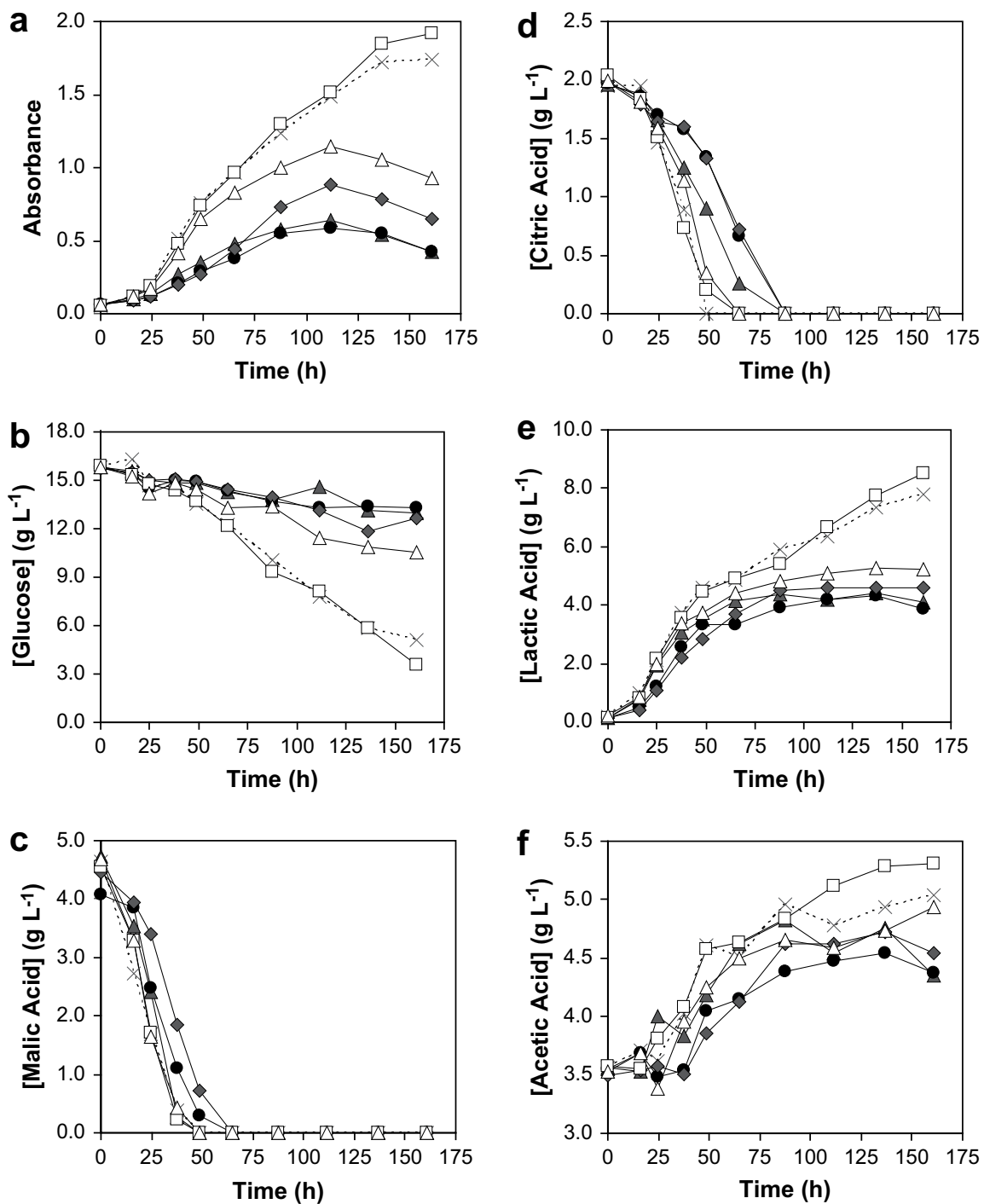

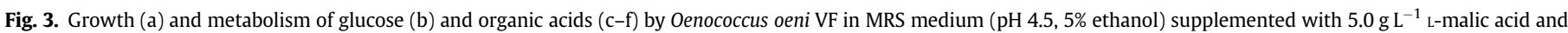
$500 \mathrm{mg} \mathrm{L}^{-1}$ phenolic acids: $(\Delta)$ caffeic acid, $(\bullet)$ ferulic acid $(\bullet)$ p-coumaric acid, $(\square)$ gallic acid; $(\Delta)$ protocatechuic acid, $(\times)$ control.

experiments with 0 . oeni $\mathrm{VF}$, except for gallic acid, the presence of phenolic acids caused a small decrease in total acetic acid production comparatively to the control (Fig. 3f, Table 1). The yields of lactic acid and acetic acid production from glucose were calculated after total consumption of L-malic and citric acids and are presented in Tables 1 and 2. Analyses of variance (ANOVAs) were used to compare yield values between the different assays. The ANOVAs results showed no statistically significant differences $(p>0.05)$ in lactic acid or in acetic acid yields for L. hilgardii 5 in the absence or presence of phenolic acids.

However, statistically significant differences were found in the conversion yields obtained with $O$. oeni $\mathrm{VF}$ which were

Table 1

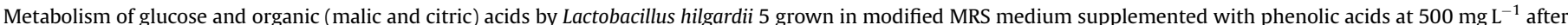
incubation at $25^{\circ} \mathrm{C}$.

\begin{tabular}{|c|c|c|c|c|c|c|c|c|}
\hline & \multicolumn{3}{|c|}{ Consumption $\left(\mathrm{mmol} \mathrm{L}^{-1}\right)$} & \multicolumn{3}{|c|}{ Production $\left(\mathrm{mmol} \mathrm{L}^{-1}\right)$} & \multirow[t]{2}{*}{ Ylac $^{\mathrm{c}}$} & \multirow[t]{2}{*}{ Yace $^{c}$} \\
\hline & Citric acid & Glucose & L-malic acid & Lactic acid & Acetic acid & Exhaustion time $(\mathrm{h})^{\mathrm{b}}$ & & \\
\hline Control & $10 \pm 4^{\mathrm{a}}$ & $94 \pm 12$ & $36 \pm 1$ & $129 \pm 9$ & $17 \pm 2$ & $48 \pm 1$ & $0.92 \pm 0.02$ & $0.03 \pm 0.02$ \\
\hline Caffeic acid & $11 \pm 3$ & $88 \pm 16$ & $37 \pm 2$ & $120 \pm 6$ & $16 \pm 3$ & $107 \pm 24$ & $0.96 \pm 0.09$ & $0.10 \pm 0.09$ \\
\hline Coumaric acid & $11 \pm 3$ & $49 \pm 7$ & $37 \pm 3$ & $94 \pm 8$ & $17 \pm 6$ & $129 \pm 18$ & $0.99 \pm 0.19$ & $0.03 \pm 0.20$ \\
\hline Ferulic acid & $9 \pm 5$ & $93 \pm 14$ & $37 \pm 3$ & $131 \pm 12$ & $17 \pm 3$ & $129 \pm 18$ & $0.95 \pm 0.07$ & $0.03 \pm 0.04$ \\
\hline Gallic acid & $10 \pm 4$ & $92 \pm 11$ & $35 \pm 1$ & $134 \pm 9$ & $19 \pm 5$ & $61 \pm 6$ & $0.93 \pm 0.00$ & $0.07 \pm 0.04$ \\
\hline Protocatechuic acid & $10 \pm 3$ & $93 \pm 14$ & $36 \pm 2$ & $129 \pm 6$ & $17 \pm 1$ & $73 \pm 4$ & $0.97 \pm 0.01$ & $0.02 \pm 0.05$ \\
\hline
\end{tabular}

\footnotetext{
${ }^{\mathrm{a}}$ Mean and standard errors values of two independent experiments, after $160 \mathrm{~h}$ of incubation.

b Exhaustion time of organic (citric and L-malic) acids.

c Yields of lactic acid and acetic acid produced (in $\mathrm{mmol} \mathrm{L}^{-1}$ ) by consumed glucose molecule (in mmol $\mathrm{L}^{-1}$ ) after exhaustion of $\mathrm{L}-\mathrm{malic}$ and citric acids in the growth medium; means and standard errors obtained in two independent experiments $(n \geq 5)$.
} 
Table 2

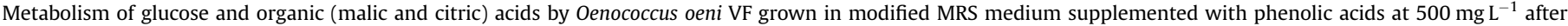
incubation at $25^{\circ} \mathrm{C}$.

\begin{tabular}{|c|c|c|c|c|c|c|c|c|}
\hline & \multicolumn{3}{|c|}{ Consumption $\left(\mathrm{mmol} \mathrm{L}^{-1}\right)$} & \multicolumn{3}{|c|}{ Production $\left(\mathrm{mmol} \mathrm{L}^{-1}\right)$} & \multirow[t]{2}{*}{ Ylac $^{\mathrm{c}}$} & \multirow[t]{2}{*}{ Yace $^{c}$} \\
\hline & Citric acid & Glucose & L-malic acid & Lactic acid & Acetic acid & Exhaustion time $(\mathrm{h})^{\mathrm{b}}$ & & \\
\hline Control & $13 \pm 4^{\mathrm{a}}$ & $50 \pm 14$ & $36 \pm 2$ & $77 \pm 10$ & $23 \pm 2$ & $52 \pm 6$ & $0.66 \pm 0.13(a)^{d}$ & $0.14 \pm 0.07$ (a) \\
\hline Caffeic acid & $13 \pm 4$ & $19 \pm 4$ & $37 \pm 2$ & $48 \pm 1$ & $21 \pm 1$ & $61 \pm 6$ & $0.63 \pm 0.24(a)$ & $1.23 \pm 0.79$ (b) \\
\hline Coumaric acid & $13 \pm 4$ & $14 \pm 1$ & $36 \pm 2$ & $48 \pm 3$ & $17 \pm 1$ & $80 \pm 11$ & $1.90 \pm 0.24(b)$ & $1.47 \pm 1.01(b)$ \\
\hline Ferulic acid & $13 \pm 3$ & $18 \pm 1$ & $36 \pm 5$ & $50 \pm 1$ & $18 \pm 4$ & $80 \pm 11$ & $1.17 \pm 0.20(c)$ & $0.94 \pm 0.32(b, c)$ \\
\hline Gallic acid & $13 \pm 3$ & $59 \pm 14$ & $35 \pm 2$ & $85 \pm 11$ & $26 \pm 4$ & $61 \pm 6$ & $0.88 \pm 0.32(\mathrm{a}, \mathrm{c})$ & $0.27 \pm 0.09(a)$ \\
\hline Protocatechuic acid & $13 \pm 4$ & $26 \pm 5$ & $38 \pm 4$ & $57 \pm 2$ & $24 \pm 1$ & $61 \pm 6$ & $0.97 \pm 0.16(\mathrm{a}, \mathrm{c})$ & $0.40 \pm 0.16(\mathrm{a}, \mathrm{c})$ \\
\hline
\end{tabular}

${ }^{\mathrm{a}}$ Mean and standard errors values of two independent experiments, after $160 \mathrm{~h}$ of incubation.

b Exhaustion time of organic (citric and L-malic) acids.

${ }^{c}$ Yields of lactic acid and acetic acid produced (in $\mathrm{mmol} \mathrm{L}^{-1}$ ) by consumed glucose molecule (in mmol $\mathrm{L}^{-1}$ ) after exhaustion of $\mathrm{L}-\mathrm{malic}$ and citric acids in the growth medium ; values represent means and standard errors obtained in two independent experiments $(n \geq 5)$

${ }^{d}$ Letters represent homogenous groups obtained after Tukey's HSD test for samples of different sizes (Spjotvoll/Stoline test) with significant differences at $p<0.05$; minimum sample size was $n=5$.

subsequently analyzed using a post-hoc comparison test. A statistically significant increase in lactic acid yield from glucose in the presence of $p$-coumaric and ferulic acids was observed, as these two results were classified in two distinct groups from the control experiment (Table 2). A similar result was obtained for the acetic acid yield from glucose in the presence of the hydroxycinnamic acids. On the other hand, hydroxybenzoic acids did not seem to affect the conversion yield of glucose to lactic and acetic acids.

The increase in acetic acid production from glucose metabolism suggest that, in the presence of hydroxycinnamic acids, there might be a shift in the glucose metabolism pathway of lactic acid bacteria towards acetate production, which would result in increased ATP production (via acetate kinase). From this it might be suggested that the increased ATP production could be important in overcoming the chemical stress caused by the presence of hydroxycinnamic acids in the growth medium. The unexpectedly high yields of lactic acid and acetic acid from glucose of 0 . oeni in the presence of hydroxycinnamic acids was also observed by other authors in other strains of this species (Rozes et al., 2003). These authors postulated that the excessive production of lactic and acetic acids could have come from the consumption of other carbohydrates present in the growth medium. Since in our experiments we also used a complex medium which contained meat and yeast extracts, the possibility of the presence of other fermentable carbohydrates from these sources cannot be excluded.

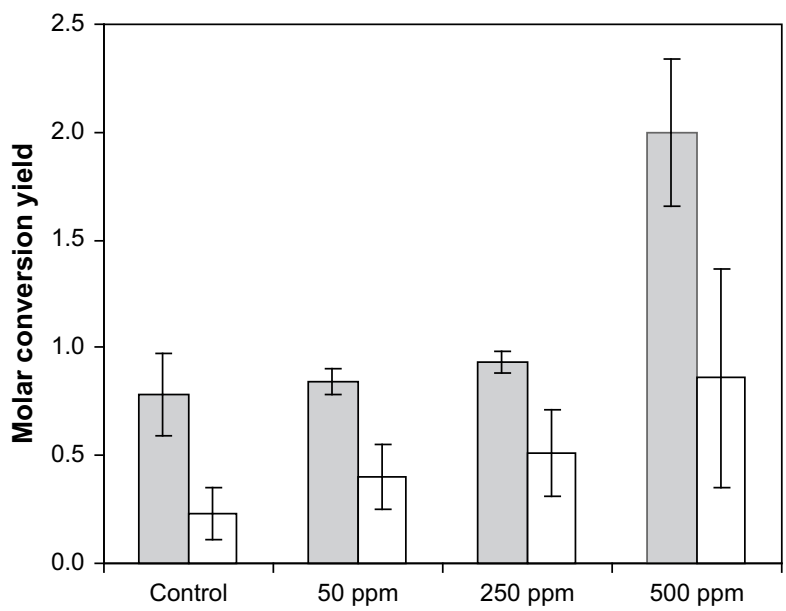

Fig. 4. Influence of $p$-coumaric acid concentration on the molar yields of organic acids produced by glucose molecule consumed by Oenococcus oeni VF grown in modified MRS medium: white bars - lactic acid yield; grey bars - acetic acid yield; bars represent means and standard errors of two independent experiments $(n \geq 4)$.
The effect of increasing concentrations of $p$-coumaric acid on the bacterial metabolism was studied. It was found for $O$. oeni $\mathrm{VF}$ that the yield of lactic acid production from glucose increased with increasing $p$-coumaric concentration (Fig. 4). No statistical difference was found between the control and the experimental assay at $50 \mathrm{mg} \mathrm{L}^{-1}$, but at higher concentrations $\left(250 \mathrm{mg} \mathrm{L}^{-1}\right.$ and $500 \mathrm{mg} \mathrm{L}^{-1}$ ), the differences were significant. The yield of acetic acid production from glucose was significantly higher than the control only when $500 \mathrm{mg} \mathrm{L}^{-1}$ of $p$-coumaric acid was used. In the case of $L$. hilgardii 5 , no significant differences were found in the production yields of lactic and acetic acids in the range of p-coumaric acid concentrations used (Fig. 5).

This study demonstrates that the presence of phenolic acids (except for gallic acid) in the growth medium has a negative effect on growth of $L$. hilgardii 5 and $O$. oeni VF. These strains were differently affected by the phenolic acids in terms of sugar and organic acids metabolism. The malolactic fermentation was only slightly affected in 0 . oeni VF while it was considerably delayed in L. hilgardii 5. An increased lactate and acetate production yield from glucose metabolism after L-malic and citric acid consumption was observed in O. oeni VF while it was not in L. hilgardii 5.

Being a selected strain used for the direct inoculation of wines, the malolactic fermentation performance of $O$. oeni VF found in this work was not unexpected. However, this strain produced higher yields of acetate from glucose in the presence of phenolic acids

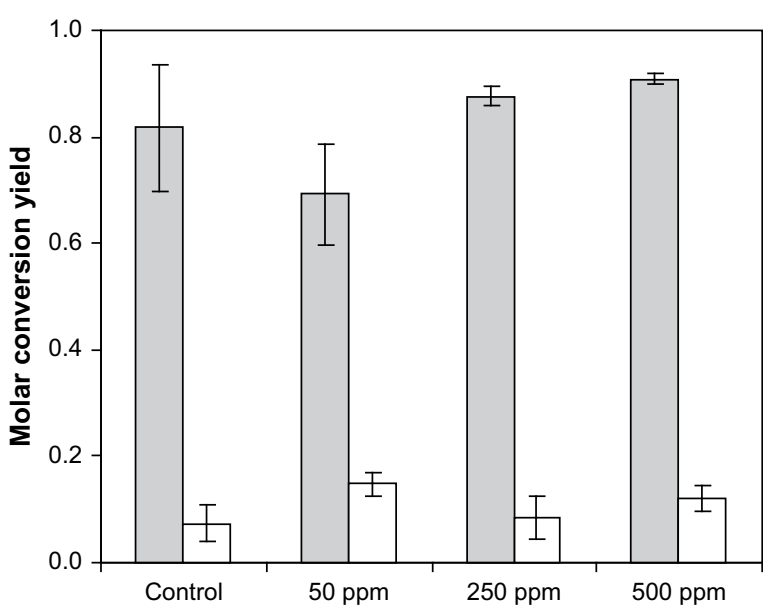

Fig. 5. Influence of $p$-coumaric acid concentration on the molar yields of organic acids produced by glucose molecule consumed by Lactobacillus hilgardii 5 grown in modified MRS medium: white bars - lactic acid yield; grey bars - acetic acid yield; bars represent means and standard errors of two independent experiments $(n \geq 4)$. 
which may lead to an increased production of volatile acidity under these circumstances. L. hilgardii is more often associated with the spoilage of Port and other fortified wines but can also be found in table wines with $\mathrm{pH}>3.5$ (Tonon and Lonvaud-Funel, 2002). In both cases the activity of this organism can increase the volatile acidity of wines beyond acceptable levels.

The level of phenolic acids in the wine may increase during malolactic fermentation due to the hydrolysis of caftaric and coutaric acids and cinammoyl-glucoside anthocyanins originally present on the grapes or from hydroxycinnamic acids extracted from oak wood used for wine ageing (Hernandez et al., 2006; Hernandez et al., 2007). Some strains of lactic acid bacteria have been shown to be able to produce volatile phenols from phenolic ( $p$-coumaric and ferulic) acids (Chatonnet et al., 1995; Couto et al., 2006). Thus, the presence of hydroxycinnamic acids in wines may influence the final composition of wines, namely due to the effect on the acetic acid and volatile phenols concentrations. The possibility of a shift on the metabolic pathway of glucose consumption caused by these compounds needs to be further investigated.

\section{Acknowledgments}

F. M. Campos would like to thank FCT (Fundação para a Ciência e a Tecnologia) for the grant PRAXIS XXI BD19909/99. The authors would also like to thank FCT for funding this research via project POCI/AGR/61331/2004 and Teresa Bilé and Filipa Sá for their help in the execution of this work.

\section{References}

Alberto, M.R., Farias, M.E., Manca De Nadra, M.C., 2001. Effect of gallic acid and catechin on Lactobacillus hilgardii $5 w$ growth and metabolism of organic compounds. J. Agric. Food Chem. 49, 4359-4363.

Campos, F.M., Couto, J.A., Hogg, T.A., 2003. Influence of phenolic acids on growth and inactivation of Oenococcus oeni and Lactobacillus hilgardii. J. Appl. Microbiol. 94, 167-174.

Chatonnet, P., Dubourdieu, D., Boidron, J.N., 1995. The influence of Brettanomyces/ Dekkera sp. yeasts and lactic acid bacteria on the ethylphenol content of red wines. Am. J. Enol. Vitic. 46, 463-468.

Couto, J.A., Campos, F.M., Figueiredo, A.R., Hogg, T.A., 2006. Ability of lactic acid bacteria to produce volatile phenols. 57, 166-171.

Couto, J.A., Hogg, T.A., 1994. Diversity of ethanol-tolerant lactobacilli isolated from Douro fortified wine - clustering and identification by numerical-analysis of electrophoretic protein profiles. J. Appl. Bacteriol. 76, 487-491.

de Revel, G., Capela, A.B., Hogg, T., 1994. A pre-spoilage marker for bacterial-activity in fortified wine, conversion of L-malic acid to L-lactic acid. Lett. Appl. Microbiol. $18,329-332$. de Revel, G., Martin, N., Pripis-Nicolau, L., Lonvaud-Funel, A., Bertrand, A., 1999. Contribution to the knowledge of malolactic fermentation influence on wine aroma. J. Agric. Food Chem. 47, 4003-4008.

Dicks, L.M.T., van Vuuren, H.J.J., 1988. Identification and physiological-characteristics of heterofermentative strains of Lactobacillus from South-African red wines. J. Appl. Bacteriol. 64, 505-513.

Fleet, G.H., 1997. Wine. In: Doyle, M.P., Beuchat, L.R., Montville, T.J. (Eds.) Food Microbiology: Fundamentals and Frontiers. ASM Press, Washington, DC USA, p. 682.

Fugelsang, K.C., 1997. Wine Microbiology. Chapman \& Hall, New York, USA.

Henick-Kling, T., 1995. Control of malo-lactic fermentation in wine: energetics, flavour modification and methods of starter culture preparation. J. Appl. Bacteriol. 79, 29S-37S.

Hernandez, T., Estrella, I., Carlavilla, D., Martin-Alvarez, P.J., Moreno-Arribas, M.V., 2006. Phenolic compounds in red wine subjected to industrial malolactic fermentation and ageing on lees. Anal. Chim. Acta 563, 116-125.

Hernandez, T., Estrella, I., Duenas, M., de Simon, B.F., Cadahia, E., 2007. Influence of wood origin in the polyphenolic composition of a Spanish red wine aging in bottle, after storage in barrels of Spanish, French and American oak wood. Eur. Food Res. Technol. 224, 695-705.

Lonvaud-Funel, A., 1999. Lactic acid bacteria in the quality improvement and depreciation of wine. Antonie Leeuwenhoek 76, 317-331.

Macheix, J.J., Fleuriet, A., Billot, J., 1990. Fruit Phenolics. CRC Press, Boca Raton, USA

Nielsen, J.C., Prahl, C., Lonvaud-Funel, A., 1996. Malolactic fermentation in wine by direct inoculation with freeze-dried Leuconostoc oenos cultures. Am. J. Enol Vitic. 47, 42-48.

Pimentel, M.S., Silva, M.H., Cortes, I., Faia, A.M., 1994. Growth and metabolism of sugar and acids of Leuconostoc oenos under different conditions of temperature and pH. J. Appl. Bacteriol. 76, 42-48.

Ramos, A., Santos, H., 1996. Citrate and sugar cofermentation in Leuconostoc oenos, a C-13 nuclear magnetic resonance study. Appl. Environ. Microbiol. 62, 2577-2585.

Reguant, C., Bordons, A., Arola, L., Rozes, N., 2000. Influence of phenolic compounds on the physiology of Oenococcus oeni from wine. J. Appl. Microbiol. 88, 1065-1071.

Richter, H., Vlad, D., Unden, G., 2001. Significance of pantothenate for glucose fermentation by Oenococcus oeni and for suppression of the erythritol and acetate production. Arch. Microbiol. 175, 26-31.

Rozes, N., Arola, L., Bordons, A., 2003. Effect of phenolic compounds on the co-metabolism of citric acid and sugars by Oenococcus oeni from wine. Lett. Appl. Microbiol. 36, 337-341.

Saguir, F.M., de Nadra, M.C.M., 1996. Organic acid metabolism under different glucose concentrations of Leuconostoc oenos from wine. J. Appl. Bacteriol. 81 393-397.

Sponholz, W.R., 1992. Wine spoilage by microorganisms. In: Fleet, G.H. (Ed.), Wine Microbiology and Biotechnology. Harwood Academic Publishers, New Jersey, USA, pp. 395-419.

Stead, D., 1993. The effect of hydroxycinnamic acids on the growth of wine-spoilage lactic-acid bacteria. J. Appl. Bacteriol. 75, 135-141.

Tonon, T., Lonvaud-Funel, A., 2002. Arginine metabolism by wine - Lactobacilli isolated from wine. Food Microbiol. 19, 451-461.

Vivas, N., Lonvaud-Funel, A., Glories, Y., 1997. Effect of phenolic acids and anthocyanins on growth, viability and malolactic activity of a lactic acid bacterium. Food Microbiol. 14, 291-299.

Zaunmuller, T., Eichert, M., Richter, H., Unden, G., 2006. Variations in the energy metabolism of biotechnologically relevant heterofermentative lactic acid bacteria during growth on sugars and organic acids. Appl. Microbiol. Biotechnol $72,421-429$. 